\title{
Late steps in secretory lysosome exocytosis in cytotoxic lymphocytes
}

\section{Peter van der Sluijs*, Mallik Zibouche and Peter van Kerkhof}

Department of Cell Biology, University Medical Center Utrecht, Utrecht, Netherlands

Edited by:

Konrad Krzewski, National Institutes

of Health, USA

Reviewed by:

Morgan Huse, Memorial

Sloan-Kettering Cancer Center, USA

Björn Önfelt, Karolinska Institutet,

Sweden

Jacques Zimmer, Centre de

Recherche Public de la Santé,

Luxembourg

${ }^{*}$ Correspondence:

Peter van der Sluiijs, Department of

Cell Biology, University Medical

Center Utrecht, Heidelberglaan 100,

Utrecht 3584 CX, Netherlands

e-mail:p.vandersluijs@umcutrecht.nl
Natural Killer cells are a subset of cytotoxic lymphocytes that are important in host defense against infections and transformed cells. They exert this function through recognition of target cells by cell surface receptors, which triggers a signaling program that results in a re-orientation of the microtubule organizing center and secretory lysosomes toward the target cell. Upon movement of secretory lysosomes to the plasma membrane and subsequent fusion, toxic proteins are released by secretory lysosomes in the immunological synapse which then enter and kill the target cell. In this minireview we highlight recent progress in our knowledge of late steps in this specialized secretion pathway and address important open questions.

Keywords: Iytic granules, secretory lysosomes, maturation, endosomes, degranulation
Natural Killer (NK) cells and cytotoxic T lymphocytes (CTL) are essential effectors of innate and adaptive immunity against infected or nascent cancer cells (1). The cytotoxic process is initiated by recognition of target cells via immune receptors and accessory plasma membrane proteins (2). CTL are activated via the $\mathrm{T}$ cell receptor (TCR) that interacts with MHC class I molecules and cognate antigenic peptides derived from target cells. NK cytotoxicity occurs via ligation of activating receptors and is kept in check by recognition of self MHC class I molecules. Cytotoxic lymphocytes use two non-redundant pathways to execute their effector functions. The first of which involves the interaction of Fas ligand on CTL and NK cells with Fas receptor on the target cell, which causes receptor oligomerization and apoptosis of the target cell (3). The second pathway also known as the lytic granule pathway represents a rapid and efficient exocytic transport route of vesicular structures containing the lytic molecules perforin and granzymes and is the focus of this minireview.

The lytic granule pathway involves the vectorial and polarized trafficking of the granules toward the immunological synapse and the re-organization of the microtubule organizing center toward the target cell and subsequent release of cytotoxic proteins. Besides the cytotoxic proteins, the granules also contain lysosomal enzymes, an acidic proteoglycan core, and lysosomeassociated membrane proteins. Since this content is released by outside in signaling, lytic granules represent a hybrid organelle with shared properties of lysosomes and secretory granules and are therefore also called secretory lysosomes or lysosome related organelles $(4,5)$.

An essential driver for the development of our understanding of the lytic pathway was the presentation of patients with Familial Hemophagocytic Lymphohistiocytosis (FHL), whose cytotoxic lymphocytes fail to kill target cells. As a consequence of which patients suffer from uncontrolled and massive lymphocyte and macrophage proliferation. A group of genes has been discovered in which mutations causes strongly impaired lytic capacity. These include RAB27A (Griscelli syndrome type 2, GS2), UNC13D (FHL3), STX11 (FHL4), and STX-BP2 (FHL5), which encode proteins of conserved families that regulate membrane trafficking (4). It is thought that the related disease phenotype of the cytotoxic lymphocytes, reflects the functional organization of the wild type forms of these proteins in a network that cooperatively regulates the degranulation pathway. Although this is a widely held belief, our understanding of the molecular mechanisms coupling their function in regulating the degranulation pathway and how they are controlled by upstream signaling is limited.

Even though NK cells and CTL functions belong to distinct arms of immunity, mutations in genes causing FHL produce dramatic yet remarkably related cytoarchitectural and immunodeficiency phenotypes. In addition, primary CTL and NK cell responses reveal similar molecular requirements $(6,7)$. Collectively this supports the notion of a common principle for granule exocytosis in cytotoxic lymphocytes on which cell-type specific layers of signaling are superimposed. We therefore will not distinguish between the lytic granule pathway in CTL and NK in our discussion.

\section{MATURATION OF SECRETORY LYSOSOMES}

Careful electronmicroscopy studies in CTL, mast cells, and melanocytes revealed a heterogenous appearance of secretory lysosomes in terms of cytoplasmic localization, size, and electron dense luminal matrix (8-10). Kinetic tracer uptake experiments and antibody labeling on ultrathin sections suggested the presence of three or more classes of secretory lysosomes, that likely represent different stages in the formation of mature 
secretory lysosomes. Secretory lysosomes are formed from precursor organelles through a series of distinct membrane transport steps that continuously deliver house-keeping content and specific effector molecules from endosomes, the trans Golgi network, and the cytoplasm (11). How the pathways between them and with other granules are regulated is only recently being explored (1215). An early stage in the formation of secretory lysosomes involves the merger of recycling endosomes containing rab11 and munc134 with late endosomes characterized by the presence of rab27a and rab7, to a so called exocytic endosome (Figure 1). The coalescence of the two endocytic structures might serve to bring exocytic traffic regulatory proteins that are needed at later stages of the secretory lysosome release. Since rab11 does not bind munc13-4 (13), other small GTPases could provide a link between munc13-4 and the endosomal system. Rab15 an endosome-localized rab (16) might take on this task as it binds to munc13-4 and coregulates with rab27 the exocytosis of von Willebrandt factor from WeibelPalade bodies (17), the secretory lysosomes of endothelial cells.

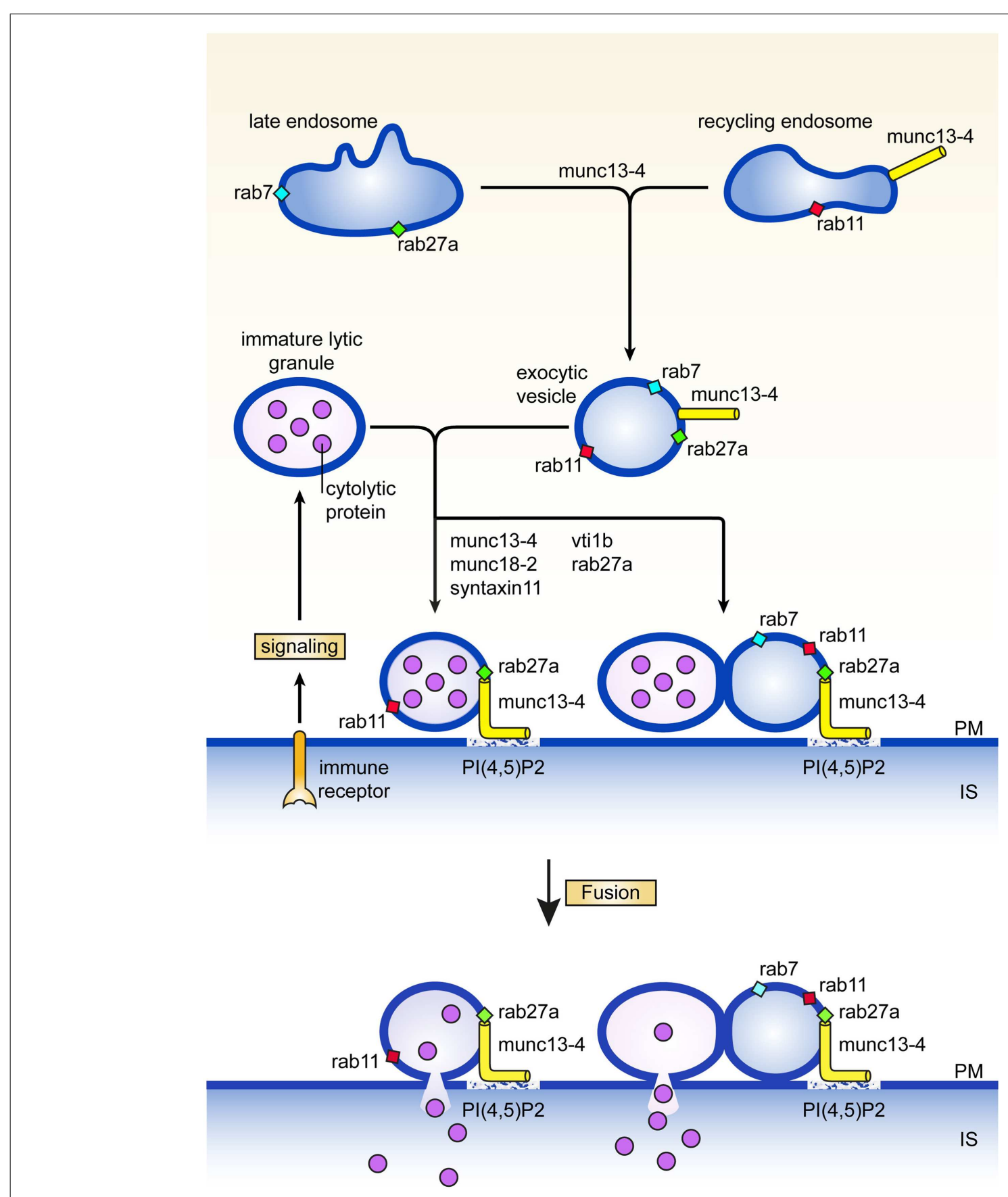

FIGURE 1 | Maturation and fusion. Pathways and proteins regulating various aspects of the maturation and fusion of secretory lysosomes (see text for details). PM denotes plasma membrane, IS immunological synapse. 
The tetrameric adaptor complex AP-1 and kinesin KIF13A represent two other membrane traffic regulators through recycling endosomes that have been implicated in the function of secretory lysosomes (18). A complex of AP-1 and KIF13A is thought to define a recycling endosomal domain partially overlapping with rab11 (18) that could facilitate cargo sorting. The AP- $1^{\star}$ KIF13A complex positions endosomes close to secretory lysosomes in the cell periphery thereby facilitating interorganellar connections.

\section{TETHERING SECRETORY LYSOSOMES AT THE PLASMA MEMBRANE}

A second step in secretory lysosome maturation occurs when the cytotoxic lymphocyte engages itself in an interaction with a target cell during which the exocytic endosomes and associated exocytic machinery move to the immunological synapse in parallel with organelles containing LAMPs, perforin, and granzymes. At least two scenarios are compatible with the available data for the next stage in the secretory lysosome maturation pathway. The two organelles may fuse with each other to generate a structure with lytic and exocytic potential at the immunological synapse. Alternatively, tethering of the exocytic endosome equipped with munc13-4, rab27, and rab11, to the lytic precursor organelle with perforin and granzyme (without actual fusion) is already sufficient to assemble and concentrate the protein machinery for efficient docking and fusion at the plasma membrane (Figure 1). Enhanced tethering of secretory lysosomes that are paired with TCR-containing endosomes has been observed at the immunological synapse of CTL. In effect tethering prolongs the dwelling time of the organelle at the immunological synapse which facilitates the subsequent fusion step with the plasma membrane, and release of lytic content (19). In support of this notion, we uncovered a second role for munc13-4 in tethering secretory lysosomes at the cell surface that is regulated independently from the upstream function of munc13-4 on recycling endosomes. Total Internal Reflection Fluorescence microscopy of cells expressing munc13-4 point mutants defective in rab27a-binding revealed that secretory lysosomes are severely impaired in the characteristic stalling behavior seen upon initiation of immune receptor signaling, showing that a complex between munc13-4 and rab27a is required for the tethering role of munc13-4 at the plasma membrane (12). In neutrophils, munc13-4 was also found to limit mobilization of rab27a positive granules after lipopolysaccharide stimulation and to restrict them at the plasma membrane (20), suggesting a more general role of the rab $27^{\star}$ munc13-4 complex in immune cells.

Molecular insight into the question as to how munc13-4 could serve as a tethering molecule derived from computational structure predictions which revealed very weak homology between the MUN domain and subunits of intracellular membrane tethering complexes (21). The MUN domain is the central region of munc13-4 that is interspaced between the $\mathrm{C} 2 \mathrm{~B}$ and $\mathrm{C} 2 \mathrm{C}$ domains (Figure 2). It contains two conserved munc homology domain sequences (22) that constitute an autonomously folding MUN domain. The MUN domain is conserved in all munc13's and related proteins and is principally involved in the priming function. The subsequent structure of the MUN domain (23) revealed that it folds into a two-stacked helical bundle, characteristic for the

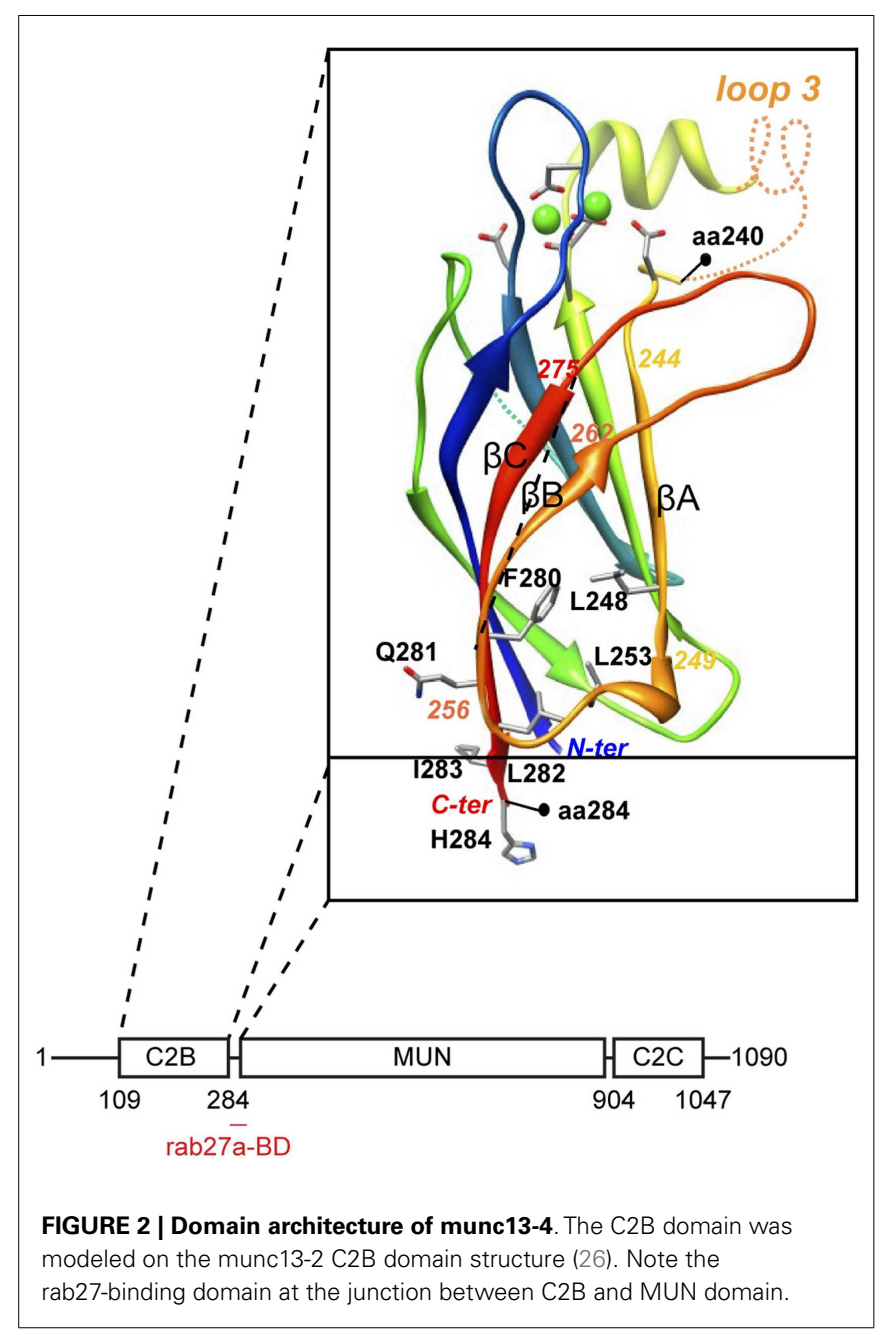

exocyst subunit sec6 and other members of the CATCHR family (complex associated with tethering containing helical rods) of tethering factors. Additional subunits of the oligomeric exocyst, GARP, COG, and Dsl1 tethering complex complexes (24) also fold in this structure as do the cargo binding sites of yeast type $\mathrm{V}$ myosins (25). Another common denominator in these complexes is their propensity to bind traffic regulators like rho and rab GTPases, SNAREs, and phospholipids.

We recently characterized the requirements for rab27-binding to munc13-4, and mapped the rab27-binding site to a short sequence just at the junction of the MUN and C2B domains (12) (Figure 2). Since the munc13 C2B domain engages in $\mathrm{Ca}^{2+}$ dependent $\mathrm{PI}(4,5) \mathrm{P} 2$ binding and the $\mathrm{C} 2 \mathrm{C}$ domain might constitutively bind membranes, munc13-4 could bridge two membranes via this multiplicity of interactions. CTL and NK cells express two other rab27a effectors, slp1 and slp2-a. Both are non-essential for secretory lysosome release, but they could assist in tethering since their C2 domains are important for membrane binding and they focus tightly at the immunological synapse $(27,28)$. Since the MUN domain of neuronal munc13 interacts with syntaxin-1 (26), we anticipate that munc13-4 will also bind to a (yet to be identified) syntaxin. In that vein munc13-4 mediated tethering 
could control specificity in SNARE reactions needed for secretory lysosome fusion.

In contrast to molecules on the secretory lysosome that facilitate tethering and docking at the immunological synapse, the molecular cue(s) on the partnering inner leaflet of the plasma membrane have not yet been defined. Given the analogies between cytokinesis, polarized exocytosis, and degranulation (29) we speculate that exocyst complex subunits could play a role in this pathway. Several lines of evidence are in accordance with this notion. The exocyst subunit sec15 binds directly to rab27 (30), while the capture of secretory granules depends on the rab27a effector MyRIP that interacts directly with exocyst subunits sec6 and $\sec 8$ (31, 32 ). Finally, munc13-4 localizes via its $\mathrm{C} 2 \mathrm{~B}$ domain to $\mathrm{PI}(4,5) \mathrm{P} 2$ enriched regions on the plasma membrane (33), while $\mathrm{PI}(4,5) \mathrm{P} 2$ is also key to localizing exocyst subunits sec3 (34) and exo70 (35). Thus molecules important for polarized secretion in other cell types, are implicated in the degranulation pathway through putative interactions with rab27 and munc13-4.

\section{FUSION OF SECRETORY LYSOSOMES WITH THE PLASMA MEMBRANE}

Tethering of munc13-4, rab27, and rab11 structures with LAMP containing organelles can be considered as a pre-requisite for late endosome-lysosome fusion. In CTL and macrophages this heterotypic fusion event has been shown to involve the Qb SNARE vtilb, which is required for release of secretory lysosome content $(19,36,37)$ (Figure 1). Interestingly, vtilb interacts with the Qa SNARE syntaxin-11 in macrophages, where silencing of syntaxin11 causes formation of enlarged late endosomes and inhibition of late endosome-lysosome fusion. In accordance with this function, syntaxin-11 associates predominantly with compartments of the late endosome-lysosome system in a variety of immune cells. In NK cells it colocalizes with CD-MPR in late endosomes, relocates to the immunological synapse, but is not found on lytic granules (38). In CTL syntaxin-11 localizes to an organelle close to but not on lytic granules (39), while it is found mainly in LAMP-1 and LBPA containing late endosomes in macrophages (37). Loss of syntaxin-11 function causes FHL4 in man $(40,41)$ and hemophagocytosis in mice (42-44). NK cells and CTL of FHL4 patients normally polarize their secretory lysosomes to the immunological synapse, but fail to release their content. This phenotype is very similar to munc13-4 deficiency in FHL3 patients and strongly argues that syntaxin-11 acts in the same pathway as munc13-4. Unlike for Griscelli type 2 and FHL3 patients, ultrastructural data are not yet available for cytotoxic lymphocytes of FHL4 patients or the recently established syntaxin-11 knock-out mice (42-44). Information on such features as size, position, content, number, etc., of endosomal structures and secretory lysosomes will be required for the evaluation at what stage the lytic pathway is blocked and where syntaxin-11 function is localized with respect of rab27a and munc13-4 activities.

In hemopoietic cells, syntaxin-11 interacts munc18-2 $(45,46)$, a member of the small family of SM proteins that regulate the activity of SNARE proteins for membrane fusion in time and in space (47). The localization of munc18-2 has been addressed in mast cells where it is associated with late endocytic organelles, just beneath the plasma membrane (48). Mutations in munc18-2 cause FHL5 and also reduce the amount of its partner syntaxin11, suggesting that munc18-2 acts as a chaperone that stabilizes syntaxin-11 $(45,46)$. Initially, inactivating munc18-2 mutations appeared to affect degranulation in CTL, NK cells, and neutrophils (49). More recent observations however show that patient mutations of munc18-2 do not only affect cytotoxic lymphocytes but also cause changes in the intestinal and renal epithelium resulting in severe diarrhea and renal proximal tubular dysfunction (50). The fact that additional tissues are affected in FHL5, likely reflects the more ubiquitous expression of munc18-2 compared to munc13-4, and syntaxin-11. Many of the proteins that are described above, act upstream of the final fusion event of secretory lysosomes with the plasma membrane. The implication is that the secretory lysosome pathway might interface with more general fusogenic machinery at or close to the final step. Recent observations of Rettig's lab support this idea and suggest that munc13-1 (51) and synaptobrevin 2 (52), two mediators of neuronal secretion, act at the final stage of secretory lysosome exocytosis. The daunting challenge now is to piece together which of the SNAREs and associated proteins cooperate in the final stage to fuse the secretory lysosomes with the plasma membrane.

A breakthrough in our understanding of munc13 and munc18 function came from in vitro reconstitution assays. Rizo's lab recently developed an in vitro liposome fusion assay in which they could show for the first time a dependency of fusion on munc18 and munc13 (53). Although this was accomplished in combination with SNAREs involved in synaptic vesicle fusion, it will likely provide a general explanation for the role of munc13 and munc18 proteins in membrane fusion. Ma et al. discovered that the closed form of syntaxin is clamped in a tight complex with munc1 8 and cannot bind other SNAREs. Munc13 can extract syntaxin through a interaction of the MUN domain with syntaxin and possibly munc 18 , thereby catalyzing the formation of the full syntaxin-SNAP-25-synaptobrevin complex and fusion $(26,53)$.

\section{COUPLING FUSION OF SECRETORY LYSOSOMES WITH ENDOCYTIC RETRIEVAL}

The trafficking proteins that regulate degranulation of secretory lysosomes are long lived. After exocytic release of content, these are in principle available for re-utiliatization in a next encounter with a target cell. A seminal paper from Eric Long's lab showed that lytic granules of NK cells undergo both complete and incomplete fusion with the plasma membrane, and suggests that incomplete fusion may promote efficient recycling of lytic granule membrane and proteins (54). SNAREs involved in fusion with the plasma membrane are returned by retrograde endocytic transport $(55,56)$.

It is less well understood how cytoplasmic proteins like rab27 and munc13-4 are retrieved. After fusion they can either undergo two fates, one of which involves dissociation and return through the cytoplasm via non-vesicular transport. Alternatively they may diffuse out in the plasma membrane or remain trapped in the vicinity of the fusion site and be efficiently re-internalized. Fluorescence recovery after photobleaching experiments with munc13-4 and rab27a showed that rab27a is relatively stably associated with membranes (57) and predominantly in the GTP bond form (58). The turnover of munc13-4 on secretory lysosome membrane is 
also relatively slow and decreased $\sim$ twofold after immune receptor signaling in rat basophil leukemia cells (59), suggesting that munc13-4 might be retrieved by coupling degranulation with endocytic re-uptake. In accord with this notion, Galandrini et al. recently found that munc13-4 was recycled back from $\mathrm{PI}(4,5) \mathrm{P} 2$ enriched domains at the immunological synapse by AP-2 dependent endocytosis (33). The mechanism via which this occurs is remarkably similar to synaptic vesicle protein retrieval in presynaptic neurons. CD16 stimulation of human NK cells causes transient activation of Arf6 (60) which is essential for the recruitment of PIP5K-alpha and PIP5K-gamma to the plasma membrane, the formation of $\mathrm{PI}(4,5) \mathrm{P} 2$ pools and secretion of secretory lysosomes (61). Upon fusion, granule membrane delivers munc13-4 to the PI(4,5)P2 pool generated by PIP5K-gamma (33). Presumably the association of munc13-4 depends on the $\mathrm{C} 2 \mathrm{~B}$ domain that has the ability to bind PI(4,5)P2 (62), which in turn serves as a recruitment hub for proteins regulating clathrin coated pit formation (63). Subsequent sorting processes in the endosomal system might then control delivery of re-internalized munc13-4 to its steady state localization in recycling endosomes $(12,13,64)$.

\section{POSTTRANSLATIONAL MODIFICATIONS OF TRAFFICKING PROTEINS REGULATING DEGRANULATION}

A central question is how the signals generated by cross-linking surface receptors with the corresponding ligands on target cells are transduced to the proteins that regulate transport and fusion of secretory lysosomes and how this modulates their function. SNAREs and their partners, and rabs play an essential role in degranulation, yet the mechanisms that determine the spatiotemporal control of their assembly in complexes for transport and fusion are incompletely understood. As protein kinases serve critical roles in reversible regulation of membrane transport (65), it is expected that phosphorylation of traffic proteins may modulate degranulation. In secretory lysosome exocytosis in mast cells, cross-linking of the high-affinity FcepsilonRI receptor leads to phosphorylation of SNAP-23 by IkappaB kinase 2, through a upstream PKC signaling pathway that is conserved in lymphocytes (66). Phosphorylation of SNAP-23 is essential for degranulation as ectopic expression of phospho-mimetic SNAP-23 mutant partially rescued the impaired IgE-mediated degranulation in IkappaB kinase 2-deficient mast cells $(67,68)$. Signaling cascades in platelets also cause phosphorylation of SNAP-23, which occurs on Ser95 and is a positive regulator of SNAP-23 dependent membrane fusion in vitro and platelet release in vivo (69). The gain in function of phosphorylated SNAP-23 correlates with its propensity to increase SNARE complex formation with syntaxin-11 and the R-SNARE VAMP8 that is critical for lytic granule exocytosis and cytotoxicity (36). Even though not yet shown in secretory lysosome release in immune cells, munc18-2 becomes phosphorylated during stimulatory conditions for regulated secretion in epithelial cells. As for SNAP-23, phosphorylation of munc18-2 enhances the assembly of a membrane fusion complex which serves as positive regulatory mechanism for fusion (70). Given the wide spread expression of munc18-2 (71), we anticipate that threonine/serine phosphorylation of munc18-2 and SNAP-23 has a general augmenting role in membrane fusion underlying secretory lysosome release (71).

\section{PERSPECTIVE}

The polarized secretion of lytic granule content in immune cells involves integration of major cytoarchitectural changes with precisely timed vesicular transport to the immunological synapse. Many proteins are known now that play a role in this traffic route and are important in degranulation. A major question is to understand how the signals that are initially generated upon encountering a target cell, control the proteins involved in membrane fission and fusion processes of this pathway. It is essentially unknown for instance if guanine nucleotide exchange factors (GEFs) and GTPase activating proteins (GAPs) for rab27a, and thereby the activity of the small GTPase are controlled upon signaling. This information could contribute insight in the order with which different rab27a effectors are recruited within a cell. We also need to improve our understanding where the proteins that control membrane traffic during degranulation are localized. Progress on this question will come from the application of powerful new imaging technologies that are increasingly being employed in immunological research. Ultimately such information will be crucial to annotate which step is controlled by which protein and how the network of traffic regulators cooperates in degranulation.

\section{REFERENCES}

1. Voskoboinik I, Smyth MJ, Trapani JA. Perforin mediated target cell death and immune homeostasis. Nat Rev Immunol (2006) 6:940-51. doi:10.1038/nri1983

2. Smith-Garvin JE, Koretzky GA, Jordan MS. T cell activation. Annu Rev Immunol (2009) 27:591-619. doi:10.1146/annurev.immunol.021908.132706

3. Jenkins MR, Griffiths GM. The synapse and cytolytic machinery of cytotoxic T cells. Curr Opin Immunol (2010) 22:308-13. doi:10.1016/j.coi.2010.02.008

4. de Saint Basile G, Menasche G, Fischer A. Molecular mechanisms of biogenesis and exocytosis of cytotoxic granules. Nat Rev Immunol (2010) 11:568-79. doi:10.1038/nri2803

5. Stinchcombe J, Bossi G, Griffiths GM. Linking albinism and immunity: the secrets of the secretory lysosome. Science (2004) 305:55-9. doi:10.1126/science. 1095291

6. Chattopadhyay PK, Betts MR, Price DA, Gostick E, Horton H, Roederer M, et al. The cytolytic enzymes granzyme A, granzyme B, and perforin: expression patterns, cell distribution, and their relationship to cell maturity and bright CD57 expression. J Leukoc Biol (2009) 85:88-97. doi:10.1189/jlb.0208107

7. Chiang SC, Theorell J, Entesarian M, Meeths M, Mastafa M, Al-Herz W, et al. Comparison of primary human cytotoxic T-cell and natural killer cell responses reveal similar molecular requirements for lytic granule exocytosis but differences in cytokine production. Blood (2013) 121:1345-56. doi:10.1182/blood2012-07-442558

8. Peters PJ, Geuze HJ, Van der Donk HA, Slot JW, Griffith JM, Stam NJ, et al. Molecules relevant for $\mathrm{T}$ cell-target cell interaction are present in cytolytic granules of human T lymphocytes. Eur J Immunol (1989) 19:1469-75. doi:10.1002/eji. 1830190819

9. Raposo G, Tenza D, Mecheri S, Peronet R, Bonnerot C, Desymard C. Accumulation of MHC class II molecules in mast cell secretory granules and their release upon degranulation. Mol Biol Cell (1997) 8:2631-45. doi:10.1091/mbc. 8.12.2631

10. Raposo G, Tenza D, Murphy DM, Berson JF, Marks M. Distinct protein sorting and localization to premelanosomes, melanosomes, and lysosomes in pigmented melanocytic cells. J Cell Biol (2001) 152:809-24. doi:10.1083/jcb.152.4.809

11. Benado A, Atiya YN, Sagi-Eisenberg R. Protein trafficking in immune cells. Immunobiology (2009) 214:403-21. doi:10.1016/j.imbio.2008.11.011

12. Elstak ED, Neeft M, Nehme NT, Voortman J, Cheung M, Goodarzifard M, et al. Munc13-4 rab27 complex is specifically required for tethering secretory lysosomes at the plasma membrane. Blood (2011) 118:1570-8. doi:10.1182/blood2011-02-339523

13. Menager MM, Menasche G, Romao M, Knapnougel P, Ho CH, Garfa M, et al. Secretory cytotoxic granule maturation and exocytosis require the effector protein hMunc13-4. Nat Immunol (2007) 8:257-67. doi:10.1038/nil431 
14. Sanchez-Ruiz Y, Valitutti S, Dupre L. Stepwise maturation of lytic granules during differentiation and activation of hman CD8+ T lymphocytes. PLoS One (2011) 6:e27057. doi:10.1371/journal.pone.0027057

15. Wood SM, Meeths M, Chiang SC, Bechensteen AG, Boelens JJ, Heilmann C, et al. Different NK cell activating receptors preferentially recruit rab27a or munc134 to perforin containing granules for cytotoxicity. Blood (2009) 114:4117-27. doi:10.1182/blood-2009-06-225359

16. Zuk PA, Elferink L. Rab15 differentially regulates early endocytic trafficking. J Biol Chem (2000) 275:26754-64. doi:10.1074/jbc.M000344200

17. Zografou S, Basagiannis D, Papafotika A, Shirakawa R, Horiuchi H, Auerbach $\mathrm{D}$, et al. A complete Rab screening reveals novel insights in Weibel-Palade body exocytosis. J Cell Sci (2012) 125:4780-90. doi:10.1242/jcs.104174

18. Delevoye C, Hurbain I, Tenza D, Sibarita JB, Gafsou SU, Ohno H, et al. AP-1 and KIF13A coordinate endosomal sorting and positioning during melanosome biogenesis. J Cell Biol (2009) 187:247-64. doi:10.1083/jcb.200907122

19. Qu B, Pattu V, Junker C, Schwarz EC, Bhat SS, Kummerow C, et al. Docking of lytic granules at the immunological synapse in human CTL requires Vtilb dependent pairing with CD3 endosomes. Jimmunol (2011) 186:6894-904. doi:10.4049/jimmunol.1003471

20. Johnson JL, Hong H, Monfregola J, Kiosses WB, Catz SD. Munc13-4 restricts motility of rab27a expressing vesicles to facilitate lipopolysaccharide-induced priming of exocytosis in neutrophils. J Biol Chem (2010) 286:5647-56. doi:10. 1074/jbc.M110.184762

21. Pei J, Ma C, Rizo J, Grishin NV. Remote homology between munc13 MUN domain and vesicle tethering complexes. J Mol Biol (2009) 391:509-17. doi:10. 1016/j.jmb.2009.06.054

22. Koch H, Hofmann K, Brose N. Definition of munc13-homology domains and characterization of a novel ubiquitously expressed munc13 isoform. Biochem J (2000) 349:247-53. doi:10.1042/0264-6021:3490247

23. Li W, Ma C, Guan R, Xu Y, Tomchick DR, Rizo J. The crystal structure of a munc13 C-terminal module exhibits a remarkable similarity to vesicle tethering factors. Structure (2011) 19:1443-55. doi:10.1016/j.str.2011.07.012

24. Yu IM, Hughson FM. Tethering factors as organizers of intracellular vesicular traffic. Annu Rev Cell Dev Biol (2010) 26:137-56. doi:10.1146/annurev.cellbio. 042308.113327

25. Pashkova N, Jin Y, Ramaswamy S, Weisman LS. Structural basis for myosin V discrimination between distinct cargoes. EMBO J (2006) 25:693-700. doi:10. 1038/sj.emboj.7600965

26. Ma C, Li W, Xu Y, Rizo J. Munc13 mediates the transition from the closed syntaxin-munc18 complex to the SNARE complex. Nat Struct Mol Biol (2011) 18:542-9. doi:10.1038/nsmb.2047

27. Holt O, Kanno E, Bossi G, Booth S, Daniele T, Santoro A, et al. Slp1 and slp2a localize to the plasma membrane of CTL and contribute to secretion at the immunological synapse. Traffic (2008) 9:446-57. doi:10.1111/j.1600-0854.2008. 00714.x

28. Menasche G, Menager MM, Lefebre JM, Deutsch E, Athman R, Klambert N, et al. A newly identified isoform of slp2-a associates with rab27a in cytotoxic T cells and participates to cytotoxic T cell degranulation. Blood (2008) 112:5052-62. doi:10.1182/blood-2008-02-141069

29. Stinchcombe JC, Griffiths GM. Secretory mechanisms in cell-mediated cytotoxicity. Annu Rev Cell Dev Biol (2007) 23:495-517. doi:10.1146/annurev.cellbio. 23.090506.123521

30. Wu S, Mehta SQ, Pichaud F, Bellen HJ, Quiocho FA. Sec15 interacts with rab11 via a novel domain and affects rab11 localization in vivo. Nat Struct Mol Biol (2005) 12:879-85. doi:10.1038/nsmb987

31. Goehring AS, Pedroja BS, Hinke SA, Langeberg LK, Scott JD. MyRIP anchors protein kinase A to the exocyst complex. J Biol Chem (2007) 282:33155-67. doi:10.1074/jbc.M705167200

32. Huet S, Fanget I, Jouannot O, Meireles P, Zeiske T, Larochette N, et al. MyRIP couples the capture of secretory granules by the actin-rich cell cortex and their attachment to the plasma membrane. J Neurosci (2012) 32:2564-77. doi:10.1523/JNEUROSCI.2724-11.2012

33. Capuano C, Paolini R, Molfetta R, Frati L, Santoni A, Galandrini R. PIP2dependent regulation of Munc13-4 endocytic recycling: impact on the cytolytic secretory pathway. Blood (2012) 119:4165-72. doi:10.1182/blood-2010-12324160

34. Yamashita M, Kurokawa K, Sato Y, Yamagata A, Mimura H, Yoshikawa A, et al. Structural basis for the rho and phosphoinositide dependent localization of the exocyst subunit sec3. Nat Struct Mol Biol (2010) 17:180-6. doi:10.1038/nsmb. 1722

35. Thapa N, Sun Y, Schramp M, Choi S, Ling K, Anderson RA. Phosphoinositide signaling regulates the exocyst complex and polarized integrin trafficking in directionally migrating cells. Dev Cell (2012) 22:116-30. doi:10.1016/j.devcel. 2011.10.030

36. Dressel R, Elsner L, Novota P, Kanwar N, Fischer von Mollard G. The exocytosis of lytic granules is impaired in Vtib or Vamp8 deficient CTL leading to a reduced cytotoxic activity following antigen specific activation. J Immunol (2010) 185:1005-14. doi:10.4049/jimmunol.1000770

37. Offenhauser C, Lei N, Roy S, Collins BM, Stow JL, Murray RZ. Syntaxin 11 binds Vtilb and regulates late endosome to lysosome fusion in macrophages. Traffic (2011) 12:762-73. doi:10.1111/j.1600-0854.2011.01189.x

38. Dabrazhynetskaya A, Ma J, Cacais AOG, Rudd E, Henter JI, Karre K, et al. Syntaxin 11 marks a distinct intracellular compartment recruited to the immunological synapse of NK cells to colocalize with cytotoxic granules. J Cell Mol Med (2012) 16:129-41. doi:10.1111/j.1582-4934.2011.01280.x

39. Pattu V, Qu B, Schwarz EC, Strauss B, Weins L, Bhat SS, et al. SNARE protein expression and localization in human cytotoxic T lymphocytes. Eur J Immunol (2012) 42:470-5. doi:10.1002/eji.201141915

40. Bryceson YT, Rudd E, Zheng C, Edner J, Ma D, Wood SM, et al. Defective cytotoxic lymphocyte degranulation in syntaxin-11 deficient familial hemophagocytic lymphohistiocytosis 4 (FHL4) patients. Blood (2007) 110:1906-15. doi:10.1182/blood-2007-02-074468

41. zur Stadt U, Schmidt S, Kasper B, Beutel K, Diler AS, Henter JI, et al. Linkage of familial hemophagocytic lymphohistiocytosis (FHL) type-4 to chromosome $6 \mathrm{q} 24$ and identification of mutations in syntaxin 11. Hum Mol Genet (2005) 14:827-34. doi:10.1093/hmg/ddi076

42. d'Orlando O, Zhao F, Kasper B, Orinska Z, Muller J, Hermans-Borgmeyer I, et al. Syntaxin 11 is required for NK and CD8+ T cell cytotoxicity and neutrophil degranulation. Eur J Immunol (2013) 43:194-208. doi:10.1002/eji.201142343

43. Kögl T, Müller J, Jessen B, Schmitt-Graeff A, Janka G, Ehl S, et al. Hemophagocytic lymphohistiocytosis in syntaxin 11 deficient mice: $\mathrm{T}$ cell exhaustion limits fatal disease. Blood (2013) 121:604-13. doi:10.1182/blood2012-07-441139

44. Sepulveda FE, Debeume F, Menasche G, Kurowska M, Cote M, Pachlopnik Schmid J, et al. Distinct severity of HLH in both human and murine mutants with complete loss of cytotoxic effectors Prf1, rab27a, and stx11. Blood (2013) 121:595-603. doi:10.1182/blood-2012-07-440339

45. Côte M, Ménager MM, Burgess A, Mahlaoui N, Picard C, Schaffner C, et al. Munc18-2 deficiency causes familial hemophagocytic lymphohistiocytosis type 5 and impairs cytotoxic granule exocytosis in patient NK cells. J Clin Invest (2009) 119:3765-73. doi:10.1172/JCI40732

46. zur Stadt U, Rohr J, Seifert W, Koch F, Grieve S, Pagel J, et al. Familial hemophagocytic lymphohistiocytosis type 5 (FHL-5) is caused by mutations in Munc182 and impaired binding to syntaxin 11. Am J Hum Genet (2009) 85:482-92. doi:10.1016/j.ajhg.2009.09.005

47. Südhof TC, Rothman JE. Membrane fusion: grappling with SNARE and SM proteins. Science (2009) 233:474-7. doi:10.1126/science.1161748

48. Martion-Verdeaux S, Pombo I, Iannascoli B, Roa M, Varin-Blank N, Rivera J, et al. Evidence for a role of munc18-2 and microtubules in mast cell granule exocytosis. J Cell Sci (2002) 116:325-34. doi:10.1242/jcs.00216

49. Zhao XW, Gazendam RP, Drewniak A, van Houdt M, Tool AT, van Hamme $\mathrm{JL}$, et al. Defects in neutrophil granule mobilization and bactericidal activity in familial hemophagocytic lymphohistiocytosis type 5 (FHL-5) syndrome caused by STXBP2/Munc18-2 mutations. Blood (2013) 122:109-11. doi:10. 1182/blood-2013-03-494039

50. Stepensky P, Bartram J, Barth TF, Lehmberg K, Walther P, Amann K, et al. Persistent defective membrane trafficking in epithelial cells of patients with FHL5 due to STXBP2/MUNC18-2 mutations. Pediatr Blood Cancer (2013) 60:1215-22. doi:10.1002/pbc. 24475

51. Dudenhöffer-Pfeifer M, Schirra C, Pattu V, Halimani M, Maier-Peuschel M, Marshall MR, et al. Different Munc13 isoforms function as priming factors in lytic granule release from murine cytotoxic T lymphocytes. Traffic (2013) 14:798-809. doi:10.1111/tra.12074

52. Matti U, Pattu V, Halimani M, Schirra C, Krause E, Liu Y, et al. Synaptobrevin2 is the v-SNARE required for cytotoxic T-lymphocyte lytic granule fusion. Nat Commun (2012) 4:doi:10.1038/ncomms 2467 
53. Ma C, Su L, Seven AB, Rizo J. Reconstitution of he vital functions of munc18 and munc13 in neurotransmitter release. Science (2013) 339:421-5. doi:10.1126/science. 1230473

54. Liu D, Martina JA, Wu XS, Hammer JA, Long EO. Two modes of lytic granule fusion during degranulation by natural killer cells. Immunol Cell Biol (2011) 89:728-38. doi:10.1038/icb.2010.167

55. Grote E, Kelly RB. Endocytosis of VAMP is facilitated by a synaptic vesicle targeting signal. J Cell Biol (1996) 132:537-48. doi:10.1083/jcb.132.4.537

56. Pryor PR, Jackson L, Gray SR, Edeling MA, Thompson A, Sanderson CM, et al. Molecular basis for the sorting of the SNARE VAMP7 into the endocytic clathrin coated vesicles by the ArfGAP Hrb. Cell (2008) 134:817-27. doi:10.1016/j.cell.2008.07.023

57. Handley MTW, Haynes LP, Burgoyne RD. Differential dynamics of rab3a and rab27a on secretory granules. J Cell Sci (2007) 120:973-84. doi:10.1242/jcs. 03406

58. Kondo H, Shirakawa R, Higashi T, Kawato M, Fukuda M, Kita T, et al. Constitutive GDP/GTP exchange and secretion-independent GTP-hydrolysis activity for rab27 in platelets. J Biol Chem (2006) 281:28657-65. doi:10.1074/jbc. M603227200

59. Elstak ED, te Loo M, Tesselaar K, van Kerkhof P, Loeffen J, Grivas D, et al A novel Dutch mutation in UNC13D reveals an essential role of the $\mathrm{C} 2 \mathrm{~B}$ domain in munc13-4. Pediatr Blood Cancer (2012) 58:598-605. doi:10.1002/ pbc. 23253

60. Galandrini R, Micucci F, Tassi I, Cifone MG, Cinque B, Piccoli M, et al. Arf6, a new player in FcgammaRIIIA lymphocyte mediated cytotoxicity. Blood (2005) 106:577-83. doi:10.1182/blood-2004-10-4100

61. Micucci F, Capuano C, Marchetti E, Picolli M, Frati L, Santoni A, et al. PI5KIdependent signals are critical regulators of the cytolytic secretory pathway. Blood (2008) 111:4165-72. doi:10.1182/blood-2007-08-108886

62. Him OH, Lu J, Rhee JS, Tomchick DR, Pang ZP, Wojcik SM, et al. Munc13 $\mathrm{C} 2 \mathrm{~B}$ domain is an activity-dependent $\mathrm{Ca}^{2+}$ regulator of synaptic exocytosis. Nat Struct Mol Biol (2010) 17:280-8. doi:10.1038/nsmb.1758

63. Haucke V, di Paolo G. Lipids and lipid modifications in the regulation of membrane traffic. Curr Opin Cell Biol (2007) 19:426-35. doi:10.1016/j.ceb.2007.06. 003

64. Hsu VW, Bai M, Li J. Getting active: protein sorting in endocytic recycling. Nat Rev Mol Cell Biol (2012) 13:323-8. doi:10.1038/nrm3332
65. Liberali P, Rämö P, Pelkmans L. Protein kinases: starting a molecular systems view of endocytosis. Annu Rev Cell Dev Biol (2008) 24:501-23. doi:10.1146/ annurev.cellbio.041008.145637

66. Häcker H, Karin M. Regulation and function of IKK-related kinases. Sci STKE (2006) 357:re13. doi:10.1126/stke.3572006re13

67. Hepp R, Puri N, Hohenstein AC, Crawford GL, Whiteheart SW, Roche PA. Phosphorylation of SNAP-23 regulates exocytosis from mast cells. J Biol Chem (2005) 280:6610-20. doi:10.1074/jbc.M412126200

68. Suzuki K, Verma IM. Phosphorylation of SNAP-23 by IkB kinase 2 regulates mast cell degranulation. Cell (2008) 134:485-95. doi:10.1016/j.cell.2008.05.050

69. Karim ZA, Zhang JZ, Banerjee M, Chicka MC, Hawas RA, Hamilton TR, et al. IKKB kinase phosphorylation of SNAP-23 controls platelet secretion. Blood (2013) 121:4567-74. doi:10.1182/blood-2012-11-470468

70. Liu Y, Ding X, Wang D, Deng H, Feng M, Wang M, et al. A mechanism of munc18b-syntaxin 3-SNAP25 assembly in regulated secretion. FEBS Lett (2007) 581:4318-24. doi:10.1016/j.febslet.2007.07.083

71. Kim K, Petrova YM, Scott BL, Nigam R, Agrawal A, Evans CM, et al. Munc18 is an essential gene in mice whose expression is limiting for secretion by airway epithelial and mast cells. Biochem J (2012) 446:383-94. doi:10.1042/BJ20120057

Conflict of Interest Statement: The authors declare that the research was conducted in the absence of any commercial or financial relationships that could be construed as a potential conflict of interest.

Received: 16 September 2013; paper pending published: 04 October 2013; accepted: 22 October 2013; published online: 18 November 2013.

Citation: van der Sluijs P, Zibouche $M$ and van Kerkhof $P$ (2013) Late steps in secretory lysosome exocytosis in cytotoxic lymphocytes. Front. Immunol. 4:359. doi: 10.3389/fimmu.2013.00359

This article was submitted to NK Cell Biology, a section of the journal Frontiers in Immunology.

Copyright (c) 2013 van der Sluijs, Zibouche and van Kerkhof. This is an open-access article distributed under the terms of the Creative Commons Attribution License (CC BY). The use, distribution or reproduction in other forums is permitted, provided the original author(s) or licensor are credited and that the original publication in this journal is cited, in accordance with accepted academic practice. No use, distribution or reproduction is permitted which does not comply with these terms. 